УДК 582.26

\title{
М.Д. ЖЕЖЕРА
}

Харьковский национальный ун-т им. В.Н. Каразина, каф. ботаники и экологии растений, пл. Свободы, 4, 61022 Харьков, Украина

\section{CYANOPROKARYOTA ВОДОЕМОВ ЛЕВОБЕРЕЖНОГО ПОЛЕСЬЯ (УКРАИНА)}

Приведены данные о видовом составе Cyanoprokaryota разнотипных водоемов Левобережного Полесья. Обнаружено 154 вида (160 внутривидовых таксонов) водорослей. Впервые для изученной территории указано 45 видов и внутривидовых таксонов, 12 из которых - новые для флоры Украинского Полесья.

Кл юч е в ы е с л о в а : Cyanophyta, Cyanoprokaryota, флора, реки, пойменные водоемы, пруды, болота, эфемерные водоемы, Левобережное Полесье.

\section{Введение}

В альгофлоре Украины синезеленые водоросли представлены довольно разнообразно. По числу видов они занимают третье место и насчитывают 649 видовых (797 внутривидовых) таксонов (Algae ..., 2006). Наиболее полно исследованы Cyanophyta водоемов и некоторых почв Полесья и Горного Крыма (Виноградова, 2005). Однако изученность этой группы водорослей для правобережных и левобережных областей Украинского Полесья неодинакова. Имеются работы по синезеленым водорослям Волынского, Житомирского, Киевского Полесья (Кондратьєва, 1956, 1959а, б; Коваленко, 1975, 1984, 1989), Шацкого национального природного парка (Коваленко, 1997). Для водоемов Черниговского и Новгород-Северского Полесья таких работ значительно меньше и посвящены они в основном хроококковым водорослям (Коваленко, Беликова, 1988).

Целью нашей работы было исследование Cyanophyta разнотипных водоемов левобережной части Украинского Полесья.

\section{Материалы и методы}

Материалом для данной работы послужили пробы водорослей, собранные в 2001-2004, 2008, 2010 годах в разнотипных водоемах Левобережного Полесья. Было выделено пять групп водоемов: первая группа реки, каналы, ручьи (отобрано 215 проб), вторая - пойменные водоемы (заливы, озера, старицы - 115 проб), третья - болота, торфяные карьеры (112), четвертая - пруды, речные запруды (85), пятая группа - эфемерные водоемы (39 проб). Всего было собрано 567 проб водорослей разных экологических групп (планктон, перифитон, бентос, выжимки из мхов). Сбор и обработку проб проводили стандартными методами в живом и фиксированном состоянии (фиксатор - 2-4\%-ный раствор () М.Д. Жежера, 2013 
формальдегида). В работе использовали световой микроскоп Биолам. Идентификацию видов проводили с помощью определителей синезеленых водорослей (Голлербах и др., 1953; Кондратьєва, 1968; Кондратьєва та ін., 1984). Для каждого вида указывали коэффициент встречаемости (\%) и относительное обилие по шкале Стармаха $(+-$ очень редко, вид присутствует не в каждом препарате; 1 - единично, 1-6 экземпляров в препарате; 2 - мало, 7-16 экземпляров, 3 - порядочно, 17-30 экземпляров; 4 - много, 31-50 экземпляров; 5 - очень много, абсолютное преобладание, более 50 экземпляров в препарате).

Список таксонов синезеленых водорослей представлен в соответствии с системой И. Комарека и К. Анагностидиса (Коваленко, 2009; Komárek, Anagnostidis, 2005; Komárek, Hauer, 2012).

\section{Результаты и обсуждение}

В разнотипных водоемах Левобережного Полесья (ЛП) выявлено и определено 154 вида (160 внутривидовых таксонов, ввт) синезеленых водорослей. Наибольшее число видов Cyanophyta (91 вид, 94 ввт) обнаружено в реках и каналах ЛП; почти одинаковое число - в пойменных водоемах (80 видов, 84 ввт), болотах и торфяных карьерах (83 вида, 85 ввт); в прудах и речных запрудах - 63 вида (64 ввт), наименьшим видовым богатством характеризовались эфемерные водоемы - всего 13 видов (рис. 1).

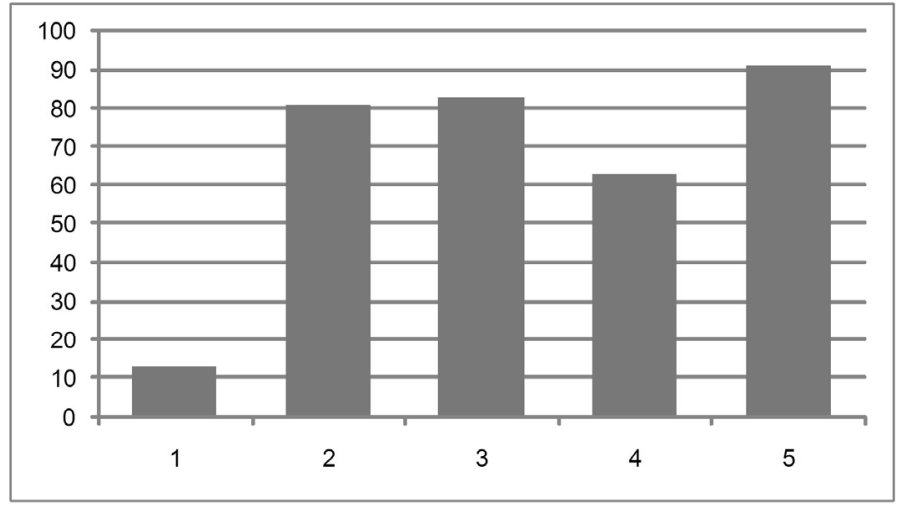

Рис. 1. Распределение видов Cyanophyta по типам водоемов: 1 - эфемерные водоемы; 2 - пойменные водоемы; 3 - болота, торфяные карьеры; 4 - пруды; 5 - реки, каналы

Коэффициент встречаемости видов колебался от 0,2 до 9,9 \%; самые высокие его значения были рассчитаны для видов Microcystis (Microcystis aeruginosa, M. wesenbergii, M. punctata), Oscillatoria tenuis, Lyngbya kuetzingii; 48 видов встречены лишь однажды (табл. 1). Более 2/3 исследованных проб (387 из 567) содержали синезеленые водоросли; среднее число видов в пробах составило 5,3, минимальное - 1 вид, максимальное -12. 
Отношение числа проб, содержащих синезеленые водоросли, к общему числу проб из данной группы водоемов было максимальным для прудов и речных запруд (84,7 \%). Для рек и каналов, а также пойменных водоемов этот показатель составил 71,6 и 70,4 \% соответственно, для болот и торфяных карьеров $-55,4 \%$, для эфемерных водоемов $-46,15 \%$.

Распределение числа видов в пробах было почти равномерным. Так, в прудах обнаружено от 1 до 9 видов водорослей, в реках, торфяных карьерах - от 1 до 8 (за исключением одной пробы из р. Днепр, в которой было найдено максимальное число видов - 12), в речных запрудах, эфемерных водоемах - от 1 до 7, каналах - 1-6, болотах - от 1 до 5 видов.

Общими для всех типов водоемов оказались 5 видов. Это Microcystis aeruginosa, Oscillatoria limnetica, O. pseudogeminata, O. tenuis и Nodularia harveyana.

Только в реках и каналах было обнаружено 23 вида, в болотах и торфяных карьерах - 19 видов, в пойменных водоемах - 13, в прудах и речных запрудах -8 . Единственным видом, найденным исключительно в эфемерных водоемах, оказалась Oscillatoria gracilis. Среди видов, найденных только в реках, наибольшим видовым разнообразием отличалась Oscillatoria, насчитывающая 9 видов. С высоким относительным обилием в реках отмечены Calothrix stagnalis (5 баллов), C. gypsophila (4 балла). По литературным данным (Клоченко, Иванова, 2009), для р. Десны приводятся 29 планктонных видов Cyanophyta. Нами обнаружено 20 видов, общими оказались пять видов (Merismopedia tenuissima, Coelomoron pusillum, Snowella lacustris, Oscillatoria chalybea, O. tenuis). Всего (с учетом литературных и оригинальных данных) для р. Десны известно 44 вида Cyanophyta.

Девятнадцать видов водорослей из 12 родов найдены исключительно в болотах. Это были виды, характерные как для болот (Stigonema minutum, S. ocellatum f. hypnicola), так и для других водоемов. Относительное обилие большинства синезеленых составило 1-2 балла, и только Calothrix braunii достигал массового развития (4 балла).

При сравнении видового состава синезеленых водорослей разных типов водоемов были использованы меры включения. Отношения включения или сходства между объектами определялись с помощью трех пороговых величин $(\delta=0,5 ; 0,6 ; 0,7)$. При пороге 0,5 все водоемы были связаны отношениями включения либо сходства (рис. 2). Так, пойменные водоемы и реки проявляли отношения сходства со всеми типами водоемов, кроме эфемерных. Последние характеризовались только отношениями включения, что объясняется малым числом видов водорослей в них. При пороге 0,6 число связей уменьшается. Так, отношение сходства сохраняется только между реками и пойменными водоемами, утрачиваются отношения включения для пар болота - реки и болота - пруды. При самом высоком пороге 0,7 отношений сходства между разными типами водоемов уже нет, и если реки, пойменные водоемы и пруды еще сохраняют связи, то болота уже не имеют ни одной 
связи с другими водоемами, что подчеркивает своеобразную альгофлору болот и торфяных карьеров.

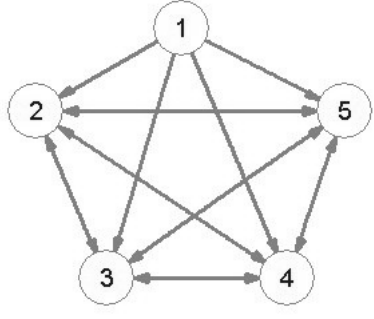

Порог 0,5

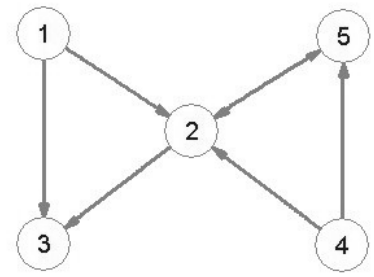

Порог 0,6

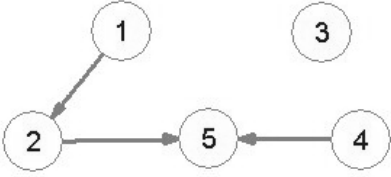

Порог 0,7

Рис. 2. Графы отношений сходства-включения альгофлоры Cyanophyta разнотипных водоемов (обозначения см. на рис. 1)

Распределение видов по экологическим группировкам почти равномерное. Так, в бентосе и перифитоне обнаружено 102 и 104 вида, в планктоне - 92 вида. Расчет коэффициента Жаккара показал, что видовой состав планктона отличался от бентоса $\left(K_{\mathrm{j}}=0,46\right)$ и перифитона $(0,45)$, а виды бентоса и перифитона проявляли сходство $(0,55)$.

Среди планктонных водорослей массового развития достигали: Microcystis aeruginosa, M. flos-aquae, M. wesenbergii, Romeria leopoliensis, Lyngbya contorta, Anabaena flos-aquae, Aphanizomenon flos-aquae и другие (см. таблицу); среди перифитона - Lyngbya kuetzingii, L. martensiana f. martensiana, Phormidium retzii, Homoeothrix varians, Calothrix fusca, C. stagnalis; среди бентоса это были Oscillatoria acutissima, O. amphibia, O. granulata, O. princeps, O. tenuis, Phormidium autumnale, Cylindrospermum stagnale.

Согласно литературным данным (Algae ..., 2006), 64 представителя синезеленых водорослей, обнаруженных нами в водоемах ЛП, являются космополитами. Один из них, Stigonema minutum, - редкий для Украины. К редким относятся 19 видов и разновидностей синезеленых водорослей (для них отмечено 1-4 местонахождения на территории Украины, см. таблицу); а три вида (Gloeotrichia spiroides, Nostoc cuticulare f. polymorphum, Synechocystis minima) известны только из водоемов Полесья.

Впервые для изученной территории указано 45 видов и разновидностей (см. таблицу, рис. 3), 12 из которых - новые для флоры Украинского Полесья: Aphanocapsa pulverea (Черниговская, Сумская области, пруды, болота, торфяные карьеры); Chroococcus vacuolatus (Черниговская обл., Корюковский р-н, окр. с. Охрамиевичи, болото), редкий вид, ранее обнаружен в степной зоне; Oscillatoria beggiatoiformis f. phormidioides (Черниговская обл., Бахмачский р-н, с. Митченки, лужа); Microcoleus tenerrimus, ранее известный из морей и соленых водоемов и почв (Черниговская обл., Щорский р-н, окр. с. Елино, р. Канава Боевая); 
Pseudanabaena schmidlei, редкий вид (Черниговская обл., Корюковский p-н, с. Белошицкая Слобода, р. Слоут); Anabaena oscillariodes (Черниговская обл., Репкинский р-н, пгт Замглай, лужа; Сумская обл., СерединоБудский р-н, окр. с. Улицы, лужа); A. oscillariodes f. stenospora (Сумская обл., Середино-Будский р-н, окр. с. Очкино, старица р. Десна); Anabaenopsis elenkinii (Черниговская обл., Сосницкий р-н, с. Хлопяники, пруд; Корюковский р-н, пгт Холмы, речная запруда); Nodularia harveyana (Черниговская обл., Сумская обл., реки, каналы, торфяные карьеры, пруды, лужи); Homoeothrix margalefii, редкий вид (Черниговская обл., Борзнянский р-н, окр. сел Гришовка и Ядуты, оз. Трубин), $H$. varians (Черниговская, Сумская обл., реки, пруд, озеро).

Cyanophyta, выявленные в разнотипных водоемах Левобережного Полесья

\begin{tabular}{|c|c|c|c|c|c|c|}
\hline \multirow[b]{2}{*}{ Таксон } & \multicolumn{6}{|c|}{ Относительное обилие } \\
\hline & 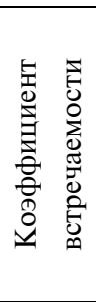 & 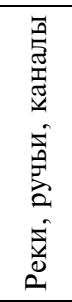 & 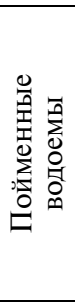 & 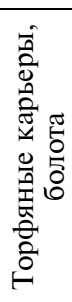 & 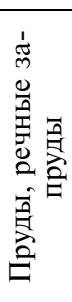 & 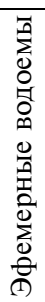 \\
\hline 1 & 2 & 3 & 4 & 5 & 6 & 7 \\
\hline Anabaena augstumalis Schmidle ${ }^{1,2}$ & 0,2 & & & & 1 & \\
\hline $\begin{array}{l}\text { A. bergii Ostenf. var. minor (Kisselev) } \\
\text { Kossinsk. }{ }^{1,2}\end{array}$ & 0,5 & $1-2$ & 1 & & & \\
\hline A. inaequalis (Kütz.) Bornet et Flahault & 0,5 & & & $3-5$ & 1 & \\
\hline $\begin{array}{l}\text { A. oscillarioides Bory ex Bornet et Fla- } \\
\text { hault }^{1}\end{array}$ & 0,4 & & & 1 & & 1 \\
\hline $\begin{array}{l}\text { A. oscillarioides Bory ex Bornet et Fla- } \\
\text { hault f. stenospora (Bornet et Flahault) } \\
\text { Elenkin }^{1,2}\end{array}$ & 0,2 & & 3 & & & \\
\hline A. scheremetievi Elenkin & 1,8 & +-3 & 1 & & $1-3$ & \\
\hline $\begin{array}{l}\text { A. sphaerica Bornet et Flahault f. } \\
\text { sphaerica }\end{array}$ & 0,2 & & 1 & & & \\
\hline $\begin{array}{l}\text { A. sphaerica Bornet et Flahault f. } \\
\text { conoidea } \text { Elenkin }^{1,2}\end{array}$ & 0,4 & 2 & & & 1 & \\
\hline Anabaenopsis elenkinii V.V. Mill. ${ }^{1}$ & 0,7 & & & & 1 & \\
\hline $\begin{array}{l}\text { Aphanizomenon flos-aquae Ralfs ex } \\
\text { Bornet et Flahault }\end{array}$ & 3,5 & +-2 & 1 & & +-5 & \\
\hline $\begin{array}{l}\text { Aphanocapsa conferta (West et } \\
\text { G.S. West) Komárk.-Legn. et Cronberg }\end{array}$ & 0,4 & & & 1 & & \\
\hline $\begin{array}{l}\text { A. incerta (Lemmerm.) Cronberg et } \\
\text { Komárek }\end{array}$ & 0,7 & & 1 & $1-3$ & 3 & \\
\hline
\end{tabular}




\begin{tabular}{|c|c|c|c|c|c|c|}
\hline 1 & 2 & 3 & 4 & 5 & 6 & 7 \\
\hline Aphanocapsa nubilum Komárek et Kling & 0,2 & & & 1 & & \\
\hline A. parasitica (Kütz.) Komárek et Anagn. & 0,2 & & & 1 & & \\
\hline${ }^{1}$ A. pulverea Koval. & 3 & & +-1 & $1-2$ & +-4 & \\
\hline Aphanothece stagnina (Spreng.) A. Braun & 1,2 & 1 & 2 & 1 & & \\
\hline${ }^{2}$ Aulosira implexa Bornet et Flahault & 0,2 & & & 1 & & \\
\hline${ }^{2} A$. planctonica Elenkin & 0,2 & 2 & & & & \\
\hline Calothrix braunii Bornet et Flahault & 0,2 & & & 4 & & \\
\hline${ }^{1}$ C. brevissima G.S. West & 0,2 & 1 & & & & \\
\hline C. dnjeprensis (Schirsch.) N.V. Kondrat. & 0,2 & & 1 & & & \\
\hline C. elenkinii Kossinsk. & 2,8 & +-2 & $1-4$ & 3 & $1-4$ & \\
\hline${ }^{1}$ C. fusca (Kütz.) Bornet et Flahault & 0,9 & $1-5$ & 1 & & & \\
\hline${ }^{1,2}$ C. intricata F.E. Fritsch & 0,2 & & 2 & & & \\
\hline${ }^{2}$ C. scytonemicola Tilden & 0,4 & & & 1 & & \\
\hline C. stagnalis Gomont & 0,2 & 5 & & & & \\
\hline${ }^{1}$ Chamaesiphon incrustans Grunow & 2,3 & $1-2$ & $2-3$ & & $1-4$ & \\
\hline Chroococcus limneticus Lemmerm. & 0,5 & 1 & & 1 & & \\
\hline Ch. minor (Kütz.) Nägeli & 0,4 & & 1 & 1 & & \\
\hline Ch. turgidus (Kütz.) Nägeli & 0,7 & 1 & + & & + & \\
\hline${ }^{2}$ Ch. vacuolata Skuja & 0,2 & & & 1 & & \\
\hline Coelomoron pusillum (Goor) Komárek & 2,5 & +1 & +-1 & & $1-2$ & \\
\hline Coelosphaerium kuetzingianum Nägeli & 0,4 & & & + & 1 & \\
\hline $\begin{array}{l}\text { Cuspidothrix issatschenkoi (Ussazcev) } \\
\text { Rajaniemi et al. }\end{array}$ & 1,9 & +-2 & & 1 & $1-4$ & \\
\hline $\begin{array}{l}\text { Cyanobium parvum (Mig.) Komárek et } \\
\text { al. }\end{array}$ & 0,9 & 2 & & $1-4$ & & \\
\hline Cyanothece aeruginosa (Nägeli) Komárek & 0,7 & & 1 & 1 & 1 & \\
\hline $\begin{array}{l}\text { Cylindrospermum marchicum (Lem- } \\
\text { merm.) Lemmerm. }\end{array}$ & 0,2 & & 4 & & & \\
\hline C. michailovskoense Elenkin & 0,2 & & 4 & & & \\
\hline C. muscicola (Kütz.) Bornet et Flahault & 0,2 & & 5 & & & \\
\hline C. stagnale (Kütz.) Bornet et Flahault & 1,4 & $2-3$ & 5 & $1-3$ & $2-3$ & \\
\hline${ }^{1}$ Dichothrix compacta Bornet et Flahault & 0,2 & 4 & & & & \\
\hline $\begin{array}{l}\text { Dolichospermum flos-aqauae ([Lyngb.] } \\
\text { Bréb. ex Bornet et Flahault) Wacklin, } \\
\text { Hoffmann et Komárek }\end{array}$ & 5,1 & +-4 & +-1 & 1 & $1-5$ & \\
\hline $\begin{array}{l}\text { D. spiroides (Kleb.) Wacklin, Hoffmann } \\
\text { et Komárek }\end{array}$ & 0,4 & + & & & 1 & \\
\hline $\begin{array}{l}\text { D. viguieri (Denis et Frémy) Wacklin, } \\
\text { Hoffmann et Komárek }\end{array}$ & 0,4 & & & & $1-3$ & \\
\hline Geitlerinema acutissimum (Kuff.) Anagn. & 4,9 & +-4 & +-5 & +-3 & $1-2$ & \\
\hline
\end{tabular}


продолжение таблицы

\begin{tabular}{|c|c|c|c|c|c|c|}
\hline 1 & 2 & 3 & 4 & 5 & 6 & 7 \\
\hline $\begin{array}{l}\text { Geitlerinema amphibium (C. Agardh ex } \\
\text { Gomont) Anagn. }\end{array}$ & 4,2 & +-2 & +-2 & $1-5$ & $1-5$ & \\
\hline G. lemmermanii (Wołosz.) Anagn. & 0,4 & & & +-1 & & \\
\hline $\begin{array}{l}\text { G. splendidum (Greville ex Gomont) } \\
\text { Anagn. }\end{array}$ & 1,1 & $1-3$ & 1 & + & & \\
\hline Gloeocapsa atrata Kütz. & 2,3 & 1 & $1-3$ & +-2 & +-4 & \\
\hline${ }^{1}$ G. gelatinosa Kütz. & 0,7 & 1 & 1 & 1 & & \\
\hline $\begin{array}{l}\text { Gloeotrichia natans (Hedw.) Rabenh. ex } \\
\text { Bornet et Flahault f. natans }\end{array}$ & 0,4 & 1 & 4 & & & \\
\hline $\begin{array}{l}{ }^{1,2} G . \text { natans (Hedw.) Rabenh. ex Bornet } \\
\text { et Flahaul f. gigantea (Trentep. in Kütz.) } \\
\text { Kirchn. }\end{array}$ & 0,2 & 1 & & & & \\
\hline G. pisum Thur. ex Bornet et Flahault & 0,7 & $1-3$ & +-1 & & & \\
\hline${ }^{1,2}$ G. spiroides N.V. Kondrat. & 0,2 & & & + & & \\
\hline $\begin{array}{l}{ }^{1,2} \text { Hapalosiphon fontinalis (C. Agardh) } \\
\text { Bornet emend. Elenkin } \mathrm{f} . \\
\text { totalateriramosa } \text { N.V. Kondrat. }\end{array}$ & 1,1 & 4 & & +-2 & & \\
\hline H. pumilus Kirchn. ex Bornet et Flahault & 0,9 & & 1 & $1-2$ & & \\
\hline $\begin{array}{l}\text { Heteroleibleinia kossinskajae (Elenkin) } \\
\text { Anagn. et Komárek }\end{array}$ & 3,7 & +-4 & +-3 & +-1 & $2-3$ & \\
\hline H. kuetzingii (Schmidle) Compère & 6,7 & $1-5$ & +-5 & & $1-5$ & \\
\hline $\begin{array}{l}{ }^{1,2} \text { Homoeothrix margalefii Komárek } \\
\text { et Kalina }\end{array}$ & 0,4 & 1 & 2 & & & \\
\hline${ }^{1}$ H. varians Geitler & 0,9 & $2-3$ & $2-5$ & & 4 & \\
\hline $\begin{array}{l}\text { Jaaginema geminatum (Menegh. ex Go- } \\
\text { mont) Anagn. et Komárek }\end{array}$ & 0,9 & +-1 & 3 & 1 & & \\
\hline J. gracile (Böcher) Anagn. et Komárek & 0,4 & & & & & 1 \\
\hline $\begin{array}{l}\text { J. pseudogeminatum (G. Schmid) } \\
\text { Anagn. et Komárek }\end{array}$ & 3,2 & +-2 & $1-2$ & $1-3$ & 1 & 2 \\
\hline $\begin{array}{l}\text { J. quadripunctulatum (Brühl et Biswas) } \\
\text { Anagn. et Komárek }\end{array}$ & 0,4 & 1 & 1 & & & \\
\hline $\begin{array}{l}\text { 1, }{ }^{2} \text { Komvophoron schmidlei (Jaag) Anagn. } \\
\text { et Komárek }\end{array}$ & 0,2 & 1 & & & & \\
\hline $\begin{array}{l}\text { Leptolyngbya foveolarum (Rabenh. ex } \\
\text { Gomont) Anagn. et Komárek }\end{array}$ & 0,7 & $1-2$ & 4 & & & \\
\hline L. fragile (Gomont) Anagn. et Komárek & 0,2 & & & 1 & & \\
\hline L. notata (Schmidle) Anagn. et Komárek & 1,9 & & +-1 & 1 & $1-2$ & \\
\hline L. tenuis (Gomont) Anagn. et Komárek & 0,7 & $1-5$ & & 1 & & \\
\hline $\begin{array}{l}\text { L. valderiana (Gomont) Anagn. et } \\
\text { Komárek }\end{array}$ & 1,6 & $1-3$ & $1-2$ & +-1 & & \\
\hline Limnothrix planctonica (Wołosz.) Meffert & 2,3 & +-2 & 2 & 1 & $1-2$ & \\
\hline Lyngbya aestuarii (Mert.) Liebm. & 0,5 & +-1 & & & & \\
\hline L. birgei G.M. Sm. & 0,4 & & 4 & + & & \\
\hline${ }^{1}$ L. calcarea (Tilden) Symoens & 0,2 & & 1 & & & \\
\hline
\end{tabular}


продолжение таблицы

\begin{tabular}{|c|c|c|c|c|c|c|}
\hline 1 & 2 & 3 & 4 & 5 & 6 & 7 \\
\hline $\begin{array}{l}\text { Lyngbya cincinnata (Itzigs. in } \\
\text { Lemmerm.) Compère }\end{array}$ & 1,2 & +-3 & & & & \\
\hline $\begin{array}{l}\text { L. lagerheimii (Gomont) Anagn. } \\
\text { et Komárek }\end{array}$ & 0,2 & & 1 & & & \\
\hline L. majuscula Harvey ex Gomont & 0,2 & 1 & & & & \\
\hline${ }^{2}$ L. martensiana Menegh. ex Gomont & 0,4 & & & & $2-5$ & \\
\hline Merismopedia elegans A. Braun & 1,1 & + & & $1-4$ & 1 & \\
\hline M. glauca (Ehrenb.) Kütz. & 1,2 & $2-4$ & & 1 & $1-2$ & \\
\hline${ }^{1} M$. insignis Schkorb. & 1,6 & 1 & +-2 & +-1 & 1 & \\
\hline${ }^{1} M$. minima Beck & 3,7 & $1-4$ & 1 & $1-4$ & $1-3$ & \\
\hline M. punctata Meyen in Wiegmann & 7,2 & +1 & +-2 & 1 & $1-2$ & \\
\hline M. tenuissima Lemmerm. & 1,4 & +1 & + & $1-3$ & 2 & \\
\hline${ }^{1}$ Microchaete tenera Thur. ex Bornet & 0,2 & & & 1 & & \\
\hline $\begin{array}{l}\text { Microcrocis gigas (Ryppowa) Komárek } \\
\text { et Anagn. }\end{array}$ & 0,2 & 1 & & & & \\
\hline M. irregularis (Lagerh.) Geitler & 0,4 & 1 & 1 & & & \\
\hline Microcystis aeruginosa (Kütz.) Kütz. & 9,9 & +-2 & +-5 & $1-4$ & $1-5$ & 2 \\
\hline M. flos-aquae (Wittr.) Kirchn. & 0,7 & 2 & + & & $1-4$ & \\
\hline M. ichtyoblabe Kütz. & 0,4 & & 1 & + & & \\
\hline M. wesenbergii (Komárek) Komárek & 7,9 & +-2 & +-2 & $1-3$ & $1-5$ & \\
\hline $\begin{array}{l}{ }^{1} \text { Nodularia harveyana Thur. ex Bornet } \\
\text { et Flahault }\end{array}$ & 1,8 & $1-3$ & 1 & 1 & 1 & 1 \\
\hline $\begin{array}{l}\text { N. spumigena Mert. ex Bornet et } \\
\text { Flahault }\end{array}$ & 0,4 & & & & +-1 & \\
\hline $\begin{array}{l}\text { Nostoc caeruleum Lyngb. ex Bornet et } \\
\text { Flahault }\end{array}$ & 0,4 & & & 1 & & \\
\hline $\begin{array}{l}\text { N. commune Vaucher ex Bornet et } \\
\text { Flahault }\end{array}$ & 0,4 & 1 & & 2 & & \\
\hline $\begin{array}{l}N \text {. cuticulare Bornet et Flahault } \\
\text { f. cuticulare }\end{array}$ & 0,2 & 1 & & & & \\
\hline $\begin{array}{l}{ }^{1,2} N . \text { cuticulare Bornet et Flahault f. } \\
\text { polymorphum (Kukk) N.V. Kondrat. }\end{array}$ & 0,2 & & 2 & & & \\
\hline${ }^{1} N$. edaphicum N.V. Kondrat. & 1,1 & & 2 & 1 & 1 & \\
\hline${ }^{1,2} N$. entophytum Bornet et Flahault & 0,5 & 1 & 1 & 1 & & \\
\hline N. kihlmani Lemmerm. & 0,2 & & + & & & \\
\hline N. linckia Bornet ex Bornet et Flahault & 0,9 & & $1-3$ & $1-2$ & & \\
\hline $\begin{array}{l}\text { N. microscopicum Carmich. ex Bornet } \\
\text { et Flahault }\end{array}$ & 0,7 & & & $2-3$ & & \\
\hline $\begin{array}{l}\text { N. paludosum Kütz. ex Bornet et } \\
\text { Flahault }\end{array}$ & 0,9 & & & $1-2$ & $1-2$ & \\
\hline N. punctiforme (Kütz. ex Hariot) Hariot & 1,4 & & 1 & $1-2$ & & 1 \\
\hline Oscillatoria annae V. Goor & 0,2 & + & & & & \\
\hline $\begin{array}{l}{ }^{1} \text { O. beggiatoiformis Gomont f. phormidio- } \\
\text { ides N.V. Kondrat. }\end{array}$ & 0,4 & & 1 & & & 2 \\
\hline
\end{tabular}


продолжение таблицы

\begin{tabular}{|c|c|c|c|c|c|c|}
\hline 1 & 2 & 3 & 4 & 5 & 6 & 7 \\
\hline Oscillatoria limosa J. Agardh ex Gomont & 1,9 & +-1 & +-1 & & & \\
\hline O. nitida Schkorb. & 0,2 & 2 & & & & \\
\hline O. ornata Kütz. ex Gomont & 0,2 & 1 & & & & \\
\hline O. princeps Vaucher ex Gomont & 0,9 & $3-5$ & & & 1 & \\
\hline O. sancta Kütz. ex Gomont & 0,2 & 1 & & & & \\
\hline O. setigera Aptekar & 0,2 & 1 & & & & \\
\hline O. tenuis J. Agardh ex Gomont & 6,9 & +-4 & +-5 & 1 & $1-5$ & $1-3$ \\
\hline O. ucrainica Vladim. & 0,5 & + & 1 & + & & \\
\hline $\begin{array}{l}\text { Phormidium aerugineo-caeruleum } \\
\text { (Gomont) Anagn. et Komárek }\end{array}$ & 2,1 & $1-4$ & $1-4$ & & 1 & \\
\hline Ph. ambiguum Gomont & 2,5 & $1-4$ & $1-3$ & $1-3$ & 1 & \\
\hline $\begin{array}{l}\text { Ph. amoenum Kütz. ex Anagn. } \\
\text { et Komárek }\end{array}$ & 0,2 & 1 & & & & \\
\hline $\begin{array}{l}{ }^{1} \text { Ph. animale (J. Agardh ex Gomont) } \\
\text { Anagn. et Komárek }\end{array}$ & 0,2 & 2 & & & & \\
\hline $\begin{array}{l}\text { Ph. autumnale (C. Agardh) Trevis. ex } \\
\text { Gomont }\end{array}$ & 0,5 & 1 & 2 & & & 5 \\
\hline Ph. bohneri Scmidle & 0,7 & & 1 & + & 1 & \\
\hline $\begin{array}{l}\text { Ph. breve (Kütz. ex Gomont) Anagn. } \\
\text { et Komárek }\end{array}$ & 0,4 & & 1 & & 1 & \\
\hline $\begin{array}{l}\text { Ph. chalybeum (Mert. ex Gomont) } \\
\text { Anagn. et Komárek }\end{array}$ & 0,2 & + & & & & \\
\hline $\begin{array}{l}\text { Ph. formosum (Bory ex Gomont) Anagn. } \\
\text { et Komárek }\end{array}$ & 0,2 & & & & 1 & \\
\hline${ }^{1}$ Ph. granulatum (N.L. Gardner) Anagn. & 0,5 & $2-5$ & & & & \\
\hline Ph. inundatum Kütz. ex Gomont & 0,4 & & & 3 & 1 & \\
\hline Ph. jadinianum Gomont & 0,2 & & & + & & \\
\hline Ph. molle Gomont & 0,2 & + & & & & \\
\hline $\begin{array}{l}{ }^{1} \text { Ph. okenii (J. Agardh ex Gomont) } \\
\text { Anagn. et Komárek }\end{array}$ & 1,1 & $1-3$ & 1 & & & \\
\hline $\begin{array}{l}\text { Ph. retzii (J. Agardh) Gomont ex } \\
\text { Gomont }\end{array}$ & 0,7 & $1-5$ & & + & & \\
\hline $\begin{array}{l}\text { Ph. terebriforme (J. Agardh ex Gomont) } \\
\text { Anagn. et Komárek }\end{array}$ & 0,5 & $1-2$ & & + & & \\
\hline $\begin{array}{l}{ }^{1} \text { Planktolyngbya contorta (Lemmerm.) } \\
\text { Anagn. et Komárek }\end{array}$ & 0,4 & & & & $3-5$ & \\
\hline $\begin{array}{l}\text { P. limnetica (Lemmerm.) Komárk.-Legn. } \\
\text { et Cronberg }\end{array}$ & 1,9 & $2-3$ & 3 & +-1 & $1-4$ & 1 \\
\hline $\begin{array}{l}\text { Planktothrix agardhii (Gomont) Anagn. } \\
\text { et Komárek }\end{array}$ & 0,7 & $3-4$ & & & $1-3$ & \\
\hline $\begin{array}{l}\text { Pseudanabaena limnetica (Lemmerm.) } \\
\text { Komárek }\end{array}$ & 2,1 & $1-3$ & $1-2$ & & 1 & \\
\hline $\begin{array}{l}\text { P. mucicola (Naumann et Hub.-Pest.) } \\
\text { Schwabe }\end{array}$ & 2,1 & +-2 & $2-3$ & & $1-4$ & \\
\hline
\end{tabular}


окончание таблицы

\begin{tabular}{|c|c|c|c|c|c|c|}
\hline 1 & 2 & 3 & 4 & 5 & 6 & 7 \\
\hline $\begin{array}{l}\text { Rhabdoderma lineare Schmidle et } \\
\text { Lauterborn }\end{array}$ & 0,4 & 1 & & 1 & & \\
\hline $\begin{array}{l}{ }^{1} \text { Rhabdogloea elenkinii (Y.V. Roll) } \\
\text { Komárek et Anagn. }\end{array}$ & 0,2 & & & & 1 & \\
\hline Rivularia aquatica (De Wild.) Geitler & 0,9 & & $1-2$ & 1 & & \\
\hline $\begin{array}{l}\text { Romeria elegans (Wołosz. in Koczw.) } \\
\text { Wołosz. et Koczw. ex Geitler }\end{array}$ & 0,5 & $1-2$ & & & 1 & \\
\hline R. gracilis (Koczw.) Koczw. ex Geitler ${ }^{1}$ & 1,1 & 1 & 1 & 1 & & \\
\hline R. leopoliensis (Racib.) Koczw. & 0,7 & & & & $3-5$ & 4 \\
\hline $\begin{array}{l}\text { Snowella lacustris (Chodat) Komárek et } \\
\text { Hindák }\end{array}$ & 4,6 & +1 & +-1 & $1-4$ & 1 & \\
\hline${ }^{1} S$. rosea (J. Snow) Elenkin & 0,5 & & & 1 & +-1 & \\
\hline${ }^{1}$ Spirulina abbreviata Lemmerm. & 0,4 & & & 2 & 2 & \\
\hline S. laxa G.M. Sm. & 1,1 & & 1 & $1-4$ & & 1 \\
\hline S. major Kütz. ex Gomont & 1,4 & +-3 & 1 & & & 1 \\
\hline S. subsalsa Oersted ex Gomont & 0,9 & + & & 1 & 1 & \\
\hline $\begin{array}{l}\text { 1, }{ }^{2} \text { Stigonema minutum Hassal ex Bornet } \\
\text { et Flahault }\end{array}$ & 0,2 & & & 1 & & \\
\hline $\begin{array}{l}{ }^{1,2} \text { S. ocellatum (Dillwyn) Thur. f. hypni- } \\
\text { cola N.V. Kondrat. }\end{array}$ & 0,2 & & & 2 & & \\
\hline Synechocystis aquatilis Sauv. & 0,7 & 1 & & 1 & & \\
\hline${ }^{1} S$. crassa Woron. & 0,4 & +1 & & & & \\
\hline${ }^{2} S$. minima Woron. & 0,2 & & & 2 & & \\
\hline${ }^{2}$ S. sallensis Skuja & 0,2 & & & 1 & & \\
\hline $\begin{array}{l}\text { Tolypothrix distorta Kütz. ex Bornet et } \\
\text { Flahault }\end{array}$ & 1,1 & & 1 & $1-4$ & & \\
\hline T. tenuis Kütz. ex Bornet et Flahault & 0,4 & & & +-1 & & \\
\hline $\begin{array}{l}{ }^{1} \text { Trichocoleus tenerrimus (Gomont) } \\
\text { Anagn. }\end{array}$ & 0,2 & + & & & & \\
\hline $\begin{array}{l}\text { Trichormus variabilis (Kütz. ex Bornet et } \\
\text { Flahault) Komárek et Anagn. }\end{array}$ & 0,4 & & $3-4$ & & & \\
\hline $\begin{array}{l}\text { Woronichinia compacta (Lemmerm.) } \\
\text { Komárek et Hindák }\end{array}$ & 1,8 & 1 & +-1 & $1-2$ & $1-2$ & \\
\hline$W$. naegeliana (Unger) Elenkin & 1,2 & +1 & +-1 & 2 & 1 & \\
\hline $\begin{array}{l}{ }^{1} \text { Xenotholos kerneri (Hansg.) } \\
\text { Gold-Morgan et al. }\end{array}$ & 0,2 & & 1 & & & \\
\hline
\end{tabular}

1 - Виды, впервые найденные на территории ЛП; ${ }^{2}$ - редкие для Украины виды.

\section{Выводы}

В разнотипных водоемах Левобережного Полесья обнаружено 154 вида (160 внутривидовых таксонов) синезеленых водорослей. Наибольшее 
число видов Cyanophyta (91 вид, 94 ввт) найдено в реках Левобережного Полесья. Сравнение альгофлоры разных типов водоемов показало своеобразие синезеленых водорослей болот и торфяных карьеров.

Впервые для изученной территории указано 45 видов и внутривидовых таксонов водорослей, 12 из которых - новые для флоры Украинского Полесья.

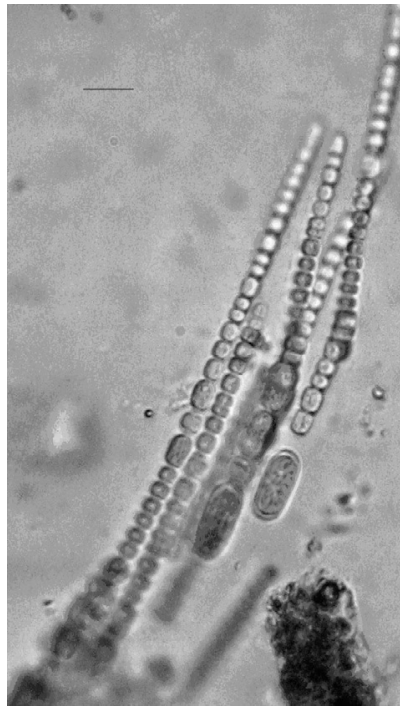

Anabaena oscillariodes

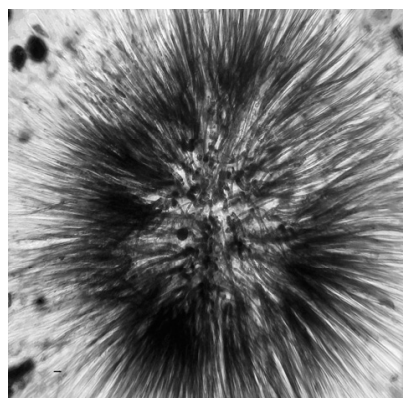

Gloeotrichia

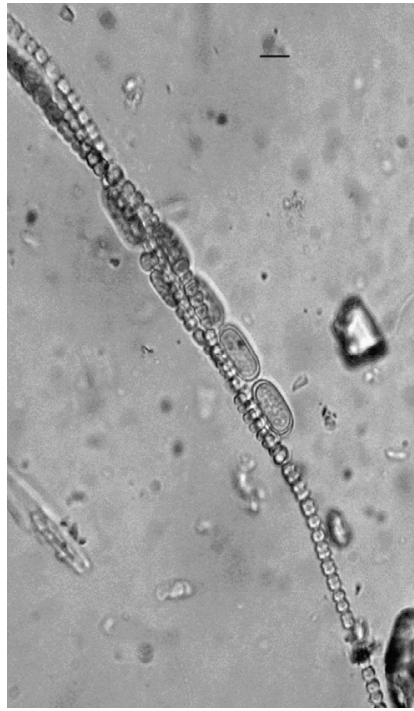

f. stenospora

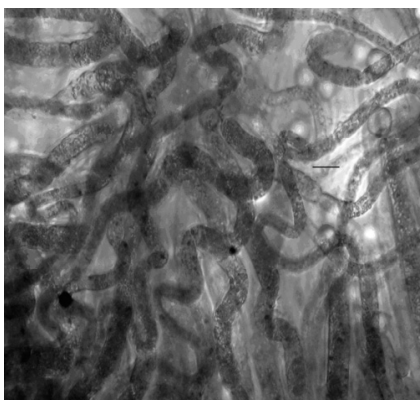

spiroides

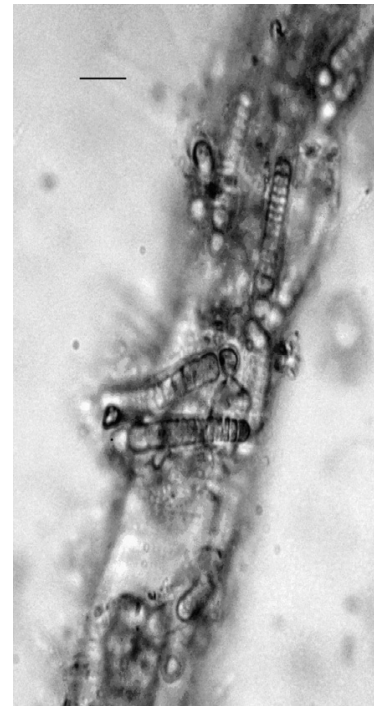

Calothrix brevissima

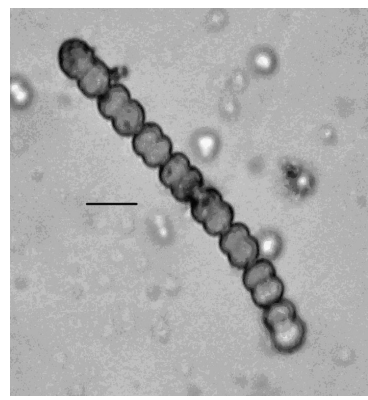

Pseudanabaena schmidlei

Рис. 3. Представители новых видов водорослей из водоемов Левобережного Полесья

\section{СПИСОК ЛИТЕРАТУРЫ}

Виноградова О.Н. Разнообразие синезеленых водорослей Украины: итоги и перспективы исследований // Актуальные проблемы современной альгологии: Тез. докл. III Междунар. конф. (20-23 апр. 2005 г.). - Харьков, 2005. - С. 28. 
Клоченко П.Д., Иванова И.Ю. Особенности видового разнообразия фитопланктона притоков Днепра // Альгология. - 2009. - 19, № 4. - С. 362-379.

Коваленко О.В. Хроококкові водорості водойм Придніпровських районів Українського Полісся // Укр. ботан. журн. - 1975. - 32, № 2. - С. 188-193.

Коваленко О.В. Хроококкові водорості водойм Волинського та Житомирського Полісся // Там же. - 1984. - 41, № 3. - С. 56-59.

Коваленко О.В., Бєлікова О.О. Хроококкові водорості водойм лівобережних районів Українського Полісся // Там же. - 1988. - 45, № 2. - С. 13-16.

Коваленко О.В. Хроококкові водорості водойм правобережних районів Українського Полісся // Там же. - 1989. - 46, № 1. - С. 45-49.

Коваленко O.B. Новые данные о Cyanophyta озер Шацкого природного национального парка (Украинское Полесье) // Альгология. - 1997. - 7, № 3. - С. 289-296.

Коваленко О.В. Флора водоростей України. Синьозелені водорості. Т. І. Спец. ч. Вип. 1. Порядок Chroococcales. - К.: Арістей, 2009. - 387 с.

Кондратьєва Н.В. Синьозелені водорості деяких боліт // Укр. ботан. журн. - 1956. 13, № 2. - С. 89-98.

Кондратьєва Н.В. Синьозелені водорості деяких оброблюваних грунтів з околиць Києва // Там же. - 1959а. - 16, № 1. - С. 74-86.

Кондратьєва Н.В. Планктонні синьозелені водорості деяких озер західноукраїнського Полісся // Там же. - 1959б. - 16, № 4. - С. 91-101.

Algae of Ukraine: diversity, nomenclature, taxonomy, ecology and geography / Eds. P.M. Tsarenko, S.P. Wasser and E. Nevo. - Ruggell: Gantner Verlag, 2006. - Vol. 1.- 712 p.

Komárek J., Anagnostidis K. Cyanoprokaryota. 2. Teil: Oscillatoriales // Süswasserflora von Mitteleuropa. - Jena, etc.: Elsevier, 2005. - Pd. 19/2. - S. 1-759.

Komárek J., Hauer T. 2012: CyanoDB.cz - On-line database of cyanobacterial genera. Word-wide electronic publication, Univ. of South Bohemia \& Inst. of Bot. AS CR, http://www.cyanodb.cz

Поступила 24 мая 2012 г.

Подписала в печать О.Н. Виноградова

\section{M.D. Zhezhera}

Department of Botany and Plant Ecology, V.N. Karazin Kharkiv Nat. Univ., 4, Svobody Sq., 61077 Kharkov, Ukraine

\section{CYANOPROKARYOTA OF WATER BODIES OF LEFT-BANK POLISSYA (UKRAINE)}

The data on cyanophycean flora of water bodies of Left-Bank Polissya have been presented. Totally 154 species (160 infr. taxa) have been found. 45 species and infraspecies taxa are first cited for studied area, among them 12 are new for Forest zone.

Key words: Cyanophyta, Cyanoprokaryota, flora, rivers, bottomland water bodies, ponds, swamps, ephemeral water bodies, Left-Bank Polissya. 